\title{
Single-nucleotide polymorphisms of uracil-processing genes affect the occurrence and the onset of recurrent depressive disorder
}

Piotr Czarny ${ }^{1}$ ， Paulina Wigner ${ }^{2}$, Justyna Strycharz ${ }^{1}$, Cezary Watala ${ }^{3}$, Ewa Swiderska ${ }^{1}$, Ewelina Synowiec ${ }^{2}$ Piotr Galecki ${ }^{4}$, Monika Talarowska ${ }^{4}$, Janusz Szemraj ${ }^{1}$, Kuan-Pin Su ${ }^{5}$, Tomasz Sliwinski ${ }^{\text {Corresp. }}{ }^{2}$

1 Department of Medical Biochemistry, Medical University of Lodz, Lodz, Poland

2 Laboratory of Medical Genetics, Faculty of Biology and Environmental Protection, University of Lodz, Lodz, Poland

3 Department of Haemostatic Disorders, Medical University of Lodz, Lodz, Poland

4 Department of Adult Psychiatry, Medical University of Lodz, Lodz, Poland

5 Department of Psychiatry and Mind-Body Interface Laboratory (MBI-Lab), China Medical University Hospital, Taichung, Taiwan

Corresponding Author: Tomasz Sliwinski

Email address: tomasz.sliwinski@biol.uni.lodz.pl

Depressive disorders (DD) are known to be associated with increased DNA damage, the impairment of DNA damage repair, and the presence of single-nucleotide polymorphisms (SNPs) in DNA damage repair genes. Some indirect evidence also suggests that uracil metabolism may be disrupted in depressed patients. Therefore, the current study genotypes three SNPs localized in genes encoding uracil-processing proteins: two glycosylases, i.e. UNG g.7245G >C (rs34259), SMUG1 c.-31A>G (rs3087404), and dUTPase, i.e. DUT g.48638795G > T (rs4775748). The polymorphisms were analyzed in 585 DNA samples (282 cases and 303 controls) using TaqMan probes. The G/G genotype and G allele of UNG polymorphism decreased the risk of depression, while the G/C genotype and $C$ allele of the same SNP increased it. It was also found that G/G carriers had their first episode significantly later than the heterozygotes. Although there was no association between the occurrence of depression and the SMUGI SNP, a significant difference was found between the homozygotes regarding the onset of DD. In conclusion, the SNPS localized in the uracil-processing genes may modulate the occurrence and the onset of depression, which further supports the hypothesis that impairment of DNA damage repair, especially base-excision repair, may play an important role in the pathogenesis of the disease. 


\section{Single-nucleotide polymorphisms of uracil-processing genes}

2 affect the occurrence and the onset of recurrent depressive

3 disorder

4 Piotr Czarny ${ }^{1}$, Paulina Wigner ${ }^{2}$, Justyna Strycharz ${ }^{1}$, Cezary Watała ${ }^{3}$, Ewa Swiderska ${ }^{1}$, Ewelina Synowiec ${ }^{2}$,

5 Piotr Galecki ${ }^{4}$, Monika Talarowska ${ }^{4}$, Janusz Szemraj ${ }^{1}$, Kuan-Pin Su${ }^{5}$, Tomasz Sliwinski ${ }^{2}$

$6 \quad{ }^{1}$ Department of Medical Biochemistry, Medical University of Lodz, Lodz, Poland

72 Laboratory of Medical Genetics, Faculty of Biology and Environmental Protection, University of Lodz,

8 Lodz, Poland

$9 \quad{ }^{3}$ Department of Haemostatic Disorders, Medical University of Lodz, Lodz, Poland

$10{ }^{4}$ Department of Adult Psychiatry, Medical University of Lodz, Lodz, Poland

$11{ }^{5}$ Department of Psychiatry and Mind-Body Interface Laboratory (MBI-Lab), China Medical University

12 Hospital, Taichung, Taiwan

14 Corresponding Author:

15 Tomasz Sliwinski ${ }^{2}$

16 ul. Pomorska 141/143, Lodz, 90-236, Poland, phone: +48 426354486, fax: +48

17 Email address: tomsliw@biol.uni.lodz.pl 


\begin{abstract}
19 Abstract
20 Depressive disorders (DD) are known to be associated with increased DNA damage, the impairment of DNA damage repair, and the presence of single-nucleotide polymorphisms

22 (SNPs) in DNA damage repair genes. Some indirect evidence also suggests that uracil 23 metabolism may be disrupted in depressed patients. Therefore, the current study genotypes three 24 SNPs localized in genes encoding uracil-processing proteins: two glycosylases, i.e. $U N G$ g. 7245G $>$ C (rs34259), SMUG1 c.-31A >G (rs3087404), and dUTPase, i.e. $D U T$ g.48638795G $>$ T (rs4775748). The polymorphisms were analyzed in 585 DNA samples (282 cases and 303 controls) using TaqMan probes. The G/G genotype and $\mathrm{G}$ allele of $U N G$ polymorphism decreased the risk of depression, while the G/C genotype and $\mathrm{C}$ allele of the same SNP increased it. It was also found that $\mathrm{G} / \mathrm{G}$ carriers had their first episode significantly later than the heterozygotes. Although there was no association between the occurrence of depression and the SMUG1 SNP, a significant difference was found between the homozygotes regarding the onset of DD. In conclusion, the SNPs localized in the uracil-processing genes may modulate the occurrence and the onset of depression, which further supports the hypothesis that impairment of DNA damage repair, especially base-excision repair, may play an important role in the pathogenesis of the disease.
\end{abstract}




\section{Introduction}

By 2020, depression (depressive disorders - DD, including recurrent ones - rDD) is predicted to be the most profound economic and social burden next to ischemic heart disease (Murray and Lopez 1997; Greden 2001). Unfortunately, despite extensive research, its pathogenesis, etiology, diagnosis and treatment remain unclear (Gruenberg et al., 2005). No cellular or molecular biomarkers exist, and so clinical diagnosis is based only on observational manifestations. In addition, one-third of patients suffers from treatment-resistant depression (Brown et al., 1994; Parker, 2000; Gruenberg et al., 2005; Akiskal and Lewis, 2005; Starkstein et al., 2005; Iwata et al., 2013; Rodrigues et al., 2014; Chang et al., 2014).

Some factors are well known to play a crucial role in depression. Inflammation, and elevated oxidative and nitrosative stress, have recently attracted much attention (Pasco et al., 2010; Gardner and Boles, 2011; Alcocer-Gómez et al., 2014; Anderson and Maes, 2014; Lu et al., 2013). These kinds of stress may induce damage to biomolecules, including nucleic acids. Accordingly, an elevated level of 8-oxoguanine (8-oxoG), a marker of oxidative DNA damage, has been found in the serum, peripheral blood mononuclear cells (PBMCs) and urine of patients suffering from clinical depression and/or depression coexisting with other non-psychiatric diseases (Irie et al., 2001; Irie et al., 2003; Forlenza and Miller, 2006; Maes et al., 2009b; Wei et al., 2009; Kupper et al., 2009; Black et al., 2015; Lindqvist et al., 2016).

Our team revealed that the PBMCs isolated from depressed patients demonstrated slower DNA damage repair efficiency (DRE) after exposure to hydrogen peroxide than controls (Czarny et al., 2015a). Moreover, we found that the presence of single-nucleotide polymorphisms (SNPs) encoding proteins involved in base excision repair (BER), a primary pathway used to ameliorate oxidative DNA damage, also appear to affect the occurrence and onset of depression (Czarny et al., 2015b; Czarny et al., 2016). Although a genotype-phenotype analysis indicated that these SNPs did not generally influence the levels of DNA damage in the patients' cells, some may still have an impact on DRE (Czarny et al., 2017a). This leads us to believe that the increased DNA damage observed in depression may be caused not only by oxidative or/and nitrosative stress, but also by the impairment of DNA damage repair pathways, particularly BER (Czarny et al., 2017b). 
The BER pathway is also responsible for the removal of uracil and its derivatives from DNA (Barnes and Lindahl, 2004; Visnes et al., 2009). Uracil DNA glycosylases (UDGs) initiate repair by recognizing and excising uracil. Several enzymes in the UDG superfamily have been identified, including uracil-N glycosylase (UNG), single-strand-specific monofunctional uracil DNA glycosylase 1 (SMUG1), methyl-binding domain glycosylase 4 (MBD4) and thymine DNA glycosylase (TDG). In addition, uracil misincorporation into DNA can be prevented by the hydrolysis of dUTP, a precursor that can be used by DNA polymerase instead of dTTP, to dUMP and diphosphate (Barnes and Lindahl, 2004). This reaction is catalyzed by dUTPase, which in humans is encoded by the DUT gene. Although there is no direct proof of an elevated uracil level in the DNA of depressed patients, several reports indicate the presence of deficiencies in folate (vitamin $\mathrm{B}_{9}$ ) and cobalamin (vitamin $\mathrm{B}_{12}$ ) (Papakostas et al., 2005; Reynolds, 2002; Beydoun et al., 2010; Kim et al., 2008; Young, 2007; Araújo et al., 2015). These vitamins are important for nucleotides biosynthesis, and their shortage may cause the balance between dTMP and dUMP to shift towards the latter (Reynolds, 2014). Finally, oxidative stress may also cause the increased presence of uracil in depressed patients’ DNA (Endres et al., 2004; An et al., 2005).

The evidence suggests, then, that depression may be associated with impairment of uracil metabolism, resulting in greater amounts of uracil being present in the DNA of those with depression. Therefore, the present study examines the possible relationship between the occurrence, onset, severity or treatment efficiency of rDD and the occurrence of three SNPs located in uracil-processing genes: g. $7245 \mathrm{G}>\mathrm{C}$ (rs34259) of the $U N G$, c.-31A $>\mathrm{G}$ (rs3087404) of the SMUG1 and g.48638795G>T (rs4775748) of the DUT.

\section{Materials and methods}

Study subjects and data collection

A total of 585 people were randomly selected to participate in the study: 282 patients diagnosed with DD and hospitalized at the Department of Adult Psychiatry of the Medical University of Lodz (Poland), and 303 healthy controls. No replacement sampling was performed. Detailed characteristics of the participants are presented in Table 1. All patients met the diagnostic criteria for depressive episode and recurrent depressive disorder according to WHO (WHO, 2015). The inclusion criteria were based on those outlined in the ICD-10 (F32.0-7.32.2, F33.0-F33.8). Prior to the start of the experiment, a standardized Composite International 
98 Diagnostic Interview (CIDI) was used to obtain a case history from each patient (Patten, 1997).

99 The severity of the disease symptoms was assessed by the 21-item Hamilton Depression Rating

100 Scale (HAM-D) (Hamilton, 1960). The intensity of the symptoms was measured in accordance

101 with Demyttenaere and De Fruyt (2003). Both the CIDI and HAM-D were performed by the

102 same psychiatrist: once before the patient was included in the study, and again after

103 antidepressant therapy with selective serotonin reuptake inhibitors (SSRIs). The exclusion

104 criteria included the presence of concurrent somatic diseases or axis I and II disorders, other than

105 depressive episodes, inflammatory or autoimmune disorders, central nervous system traumas,

106 familial prevalence of mental disorders other than recurrent depressive disorders or

107 unwillingness to give informed consent. A study group was formed of unrelated native residents

108 of central Poland.

109 Participation was voluntary, and the subjects were informed of the experiment's purpose and 110 assured of its voluntary nature. They were also informed that their personal data would be 111 confidential. All subjects gave their written consent to participate in this study. The protocol was 112 approved by the Bioethics Committee of the Medical University of Lodz (No. RNN/70/14/KE).

Selection of single-nucleotide polymorphisms

115 Selection of the polymorphisms was performed using the public domain of the database

116 for single nucleotide polymorphisms (dbSNP) of the National Center for Biotechnology

117 Information, available at http://www.ncbi.nlm.nih.gov/snp (Bethesda, MD, USA). Two criteria

118 were followed when selecting SNPs: a minor allele frequency (MAF) greater than 0.05

119 (population ID: HapMap-CEU), and a localization in either the coding or regulatory region of the 120 genes.

121

122

DNA extraction

Genomic DNA was isolated using the Blood Mini Kit (A\&A Biotechnology, Gdynia,

124 Poland) from the venous blood of depressed patients before antidepressant therapy. The purity

125 and quantity of the DNA samples was determined by measuring their absorbance at $260 \mathrm{~nm}$ and

$126280 \mathrm{~nm}$. To prevent multiple freezing and thawing, the blood was aliquoted as individual

127 samples and stored at $-20^{\circ} \mathrm{C}$. 
129 Genotyping

TaqMan SNP Genotyping Assay (Thermo Fisher Scientific, Waltham, Massachusetts, USA) and 2X Master Mix Takyon for Probe Assay - No ROX (Eurogentec, Liège, Belgium)

132

133

134

135

136

137

138

139

140

141

142

143

144

145

146

147

148

149

150

151

152

153

154

155

156

157

were used to genotype selected polymorphisms. Reactions were performed and analyzed in the Mx3005P qPCR System and MxPro QPCR Software (Agilent Technologies, Santa Clara, CA, USA).

\section{Statistical analysis}

The collected data was analyzed in Statistica 12 (Statsoft, Tulsa, OK, USA), SigmaPlot 11.0 (Systat Software Inc., San Jose, CA, USA), Resampling Stats Add-in for Excel v.4 (Arlington, VA, USA) and StudSize3.02 (CreoStat HB, Västra Frölunda, Sweden; used for power analysis). An unconditional multiple logistic regression model was used to calculate the association between case/control and each polymorphism. The results are shown as odds ratios (ORs) with $95 \%$ confidence interval $(95 \% \mathrm{CI})$. ORs were adjusted for gender, due to the fact that women are twice more likely to suffer from depression than men (Kessler, 2004). In addition, the significant outcomes were further verified with the use of two approaches: the bootstrap-boosted multiple logistic regression (resampling with replacement, 10000 iterations) and the cross-validated logistic regression (that corresponds to $d$-jackknife technique) (control group was the modeled class). This was intended to overcome any possible bias related to relatively low sample size. The goodness of fit of logistic regression models pointing for a significant discrimination between controls and patients was estimated with Hosmer-Lemeshow test.

The descriptive data presented in figures and tables are shown as means \pm SD or medians with interquartile ranges. Normality of the studied group was assessed via the ShapiroWilk test, homogeneity of variance was verified with Brown-Forsythe test, and then, accordingly, either unpaired Student's t test or Mann-Whitney $U$ test was used. In some bivariate and multivariate analyses we used the approach of resampling with replacement (the bootstrapboosted versions of the tests, 10000 iterations) to make sure that the revealed differences were not detected by a pure chance. The effect of the studied SNPs on the age of the onset of depression was evaluated in two different ways. The first approach used age as a continuous 
158 variable, while the second employed a cut-off at 35 years, an age which might be regarded as the

159 transition between young adult to middle-aged adult.

160

161

162

163

164

165

166

167

168

169

incidence.

170

Gene-gene interactions and the risk of recurrent depression disorder

173

Regarding the effect of combined genotypes, it was found that the T/T-A/A-G/C (DUT

174 (rs4775748), SMUG1 c.-31A >G (rs3087404) and $U N G$ (rs34259) carriers had an increased risk of 175

Single-nucleotide polymorphisms of genes encoding proteins involved in the removal of uracil from DNA and the age of the first episode of recurrent depressive disorder

To evaluate whether the studied SNPs could have had an impact on the onset of the disease the patients were divided according to genotype and their age of onset was compared (Fig. 1A-C). In the case of $S M U G$ c.-31A $>$ G(rs3087404), it was found that carriers of the $A / A$ genotype underwent their first episode significantly later than the G/G carriers. Similarly, in case of $U N G$ g.7245G $>C$ (rs34259), patients with a $\mathrm{G} / \mathrm{G}$ genotype had a greater age of onset than the heterozygotes. When the patients were stratified into the two groups based on age, it was found that the UNG g.7245G $>$ C (rs34259) affected the disease occurrence only in patients with early onset depression, i.e. in those under 35 years of age (Table 4). However, no statistically significant difference was found between patients with early and late onset DD (Table S1). 
188

189

190

191

192

193

194

195

196

197

198

199

200

201

202

203

204

205

206

207

208

209

210

211

212

213

214

215

216

217

218

Single-nucleotide polymorphisms of genes encoding proteins involved in the removal of uracil from DNA and the severity of recurrent depressive disorder or treatment effectiveness

No significant difference was found between patients with different genotypes of the studied genes with regard to HAM-D (Fig. 2A-C), different treatment efficiency or HAM-D score after treatment (Fig. 2D-F and 2G-I). Effectiveness of the therapy was calculated using the following formula:

$\mathrm{TE}=\frac{\left(\mathrm{HAM}-\mathrm{D}_{0}-\mathrm{HAM}-\mathrm{D}_{\mathrm{E}}\right) \times 100 \%}{\mathrm{HAM}-\mathrm{D}_{0}} ;$

where TE is treatment effectiveness, $H A M-D_{0}$ is the score obtained by the patient before therapy and $\mathrm{HAM}-\mathrm{D}_{\mathrm{E}}$ is score achieved after therapy.

\section{Discussion}

To our best knowledge, this is the first study to demonstrate that SNPs for uracilprocessing genes modulate the risk of depression. The mutagenic potential of uracil depends on its origin in DNA. Uracil is introduced into DNA either through its misincorporation by DNA polymerase during replication, or by the deamination of cytosine (Kavli et al., 2002), which has been estimated to occur 100-500 times per cell per day (Frederico et al., 1990; Lindahl, 1993). In the first case, the lesion is processed by BER, and if not repaired correctly, may lead to the production of an apurinic/apyrimidinic (AP) site or a DNA strand break (Dianov et al., 1991; Sousa et al., 2007). In addition, the replacement of thymine by uracil in a protein binding sequence may affect the affinity of these proteins to the DNA, resulting in cytotoxic properties (Verri et al., 1990). In the second case, a C:G pair becomes a 100 per cent mutagenic U:G mismatch, which has been attributed to the fact that DNA polymerases cannot distinguish between $U$ and $T$ in the template (Visnes et al., 2009). Unless it is repaired, it yields $C: G$ and U:A pairs after replication, resulting in a transition from C:G to T:A (Sousa et al., 2007).

Uracil derivatives may also possess a mutagenic character arising from oxidative stress. For example, 5-hydroxymethyluracil (5-hmeU) can be formed by the oxidation of a methyl group in thymine or deamination of 5-hydroxymethylcytosine, which is formed from 5methylocytosine $(5 \mathrm{mC})$ by its oxidation: a common modification of cytosine present in human cells which is thought to be responsible for the epigenetic regulation of gene expression (Boorstein et al., 2001). In the light of evidence that depression may be associated with 
219 disturbances in uracil metabolism, and our own previous research showing the impairment of

220 DNA repair in patients with depression, the present study evaluates whether the presence of

221 SNPs within the genes of two DNA glycosylases and that of dUTPase affect the occurrence of

222 the disease.

223 The first of the studied polymorphisms, DUT g.48346598G $>$ T (rs4775748), is located in

224 the downstream region of the gene encoding dUTPase, and is known to be significantly

225 associated with blood DNA uracil concentration (Chanson et al., 2009); more precisely, G/G

226 genotype carriers had lower levels of uracil in blood DNA than the other two genotypes. The

227 authors speculate that the location of the SNP in the 3'-untranslated region causes it to modify

228 the secondary structure of mRNA, thus influencing the stability or affinity of small RNAs to the

229 mRNA. In contrast, the present study did not find any association between this polymorphism

230 and the occurrence, the onset, the severity or the treatment efficiency of depression. However,

231 the analysis of combined genotypes revealed that the heterozygote of the DUT SNP combined

232 with heterozygote of SMUG SNP and G/G genotype of the UNG SNP decreased the incidence of

233 depression, while the T/T homozygote of the DUT SNP combined with A/A genotype of the

$234 S M U G$ SNP and heterozygote variant of the $U N G$ SNP increased it (Table 4).

The second studied SNP, SMUG1 c.-31A $>$ G(rs3087404), is located in a promoter

236 region of the gene encoding SMUG1. Although its full name - single-strand-specific

237 monofunctional uracil DNA glycosylase 1 - could indicate that this glycosylase is specific to

238 uracil in single-stranded DNA, in reality, it removes this base from both single- and double-

239 stranded DNA in the context of U:A and U:G pairs (Masaoka et al., 2003; Pettersen et al., 2007).

240 In addition, it recognizes uracil derivatives that have been formed by oxidation, i.e. 5-hmeU, 5-

241 formylouracil (foU) and 5-hydoxyuracil (hmU) (Boorstein et al., 2001; Masaoka et al., 2003).

242 SMUG1 cannot be considered only as a "backup" for UNG2, since its knock out results in an

243 increased number of mutations in mouse embryonic fibroblast (MEFs) cell line (An et al., 2005).

244 Moreover, SMUG1 was found to be involved in the metabolism of RNA, particularly ribosomal

245 RNA quality control (Jobert et al., 2013).

246 The SNP was associated with age-related macular degeneration (AMD), a

247 neurodegenerative disease causing blurred or no vision, in a Polish population (Synowiec et al.,

248 2014). The polymorphism is believed to be located in the regulatory region, and so may have an

249 impact on mRNA stability, degradation and gene expression (Nadeau, 2002; Synowiec et al., 
250

251

252

253

254

255

256

257

258

259

260

261

262

263

264

265

266

267

268

269

270

271

272

273

274

275

276

277

278

279

280

2014). However, no such association between the SNP and the occurrence of AMD was found in a study conducted on Iranian patients (Bonyadi et al., 2017). Similarly, no statistically significant difference was observed between patients and controls with regard to the distribution of alleles and genotypes of this polymorphism in the present study, and the presence of the SNP did not affect the severity of depression symptoms or the effectiveness of antidepressant treatment (Fig. 2B,E,H); however, carriers with a G/G genotype reported a significantly earlier first episode than those with A/A (Fig. 1B).

The last studied polymorphism, $U N G \mathrm{~g} .7245 \mathrm{G}>\mathrm{C}$ (rs34259), is located in the downstream region of the gene encoding two forms of UNG: a mitochondrial form (UNG1) and a nuclear one (UNG2). Both variants share a common catalytic domain, but their $N$-terminal sequences vary, resulting in different subcellular targeting (Nilsen et al., 1997). Like SMUG1, UNGs remove uracil from both single- and double-stranded DNA (Kavli et al., 2002). Moreover, UNGs recognize and excise 5-fluorouracil (5-FU) as well as oxidized pyrimidines, i.e. isodialuric acid, hmU and alloxan (Dizdaroglu et al., 1996; Krokan et al., 1997). Although $U N G-$ deficient mice are viable, they accumulate uracil in their DNA, and the mutation rate of their cells is five-times greater (Andersen et al., 2005b; Nilsen et al., 2000; An et al., 2005).

Interestingly, they develop lymphoid hyperplasia and B-cell lymphomas, indicating that the lack of UNG disrupts the adaptive immunity (Andersen et al., 2005a; Nilsen et al., 2003).

Analogically to DUT g.48346598G>T (rs4775748), the UNG SNP (rs34259) has also been found to modulate the amount of uracil in blood DNA (Chanson et al., 2009). However, while the effect of the DUT SNP best fitted a recessive model, i.e. the heterozygotes did not differ from homozygous wild-type individuals, the UNG SNP displayed a more additive effect, with $\mathrm{G} / \mathrm{G}$ genotype carriers having the lowest concentration of uracil in blood DNA, the heterozygotes a moderate level and the $\mathrm{C} / \mathrm{C}$ genotype carriers with the highest. Chanson et al speculate that variant $\mathrm{C}$ may modify the secondary structure of the mRNA, thus decreasing the level of UNG synthesis. Accordingly, in the present study, the G/G genotype and allele G decreased the risk of depression occurrence, while the G/C genotype and allele $\mathrm{C}$ increased it; however, no association was found between the occurrence of $\mathrm{C} / \mathrm{C}$ genotype and the disease, which may be due to the small number of individuals carrying this genotype. Nevertheless, this polymorphism may also affect the onset of depression: $G / G$ carriers demonstrated significantly later onset of the disease than the heterozygotes (Fig. 1C). In addition, the polymorphism was 
281 found to affect the occurrence of depression only in patients that had their first episode before 35

282 years of age, while no association was found in patients with the first episode at or after 35 years

283 of age (Table 3). This could indicate that the $\mathrm{G} / \mathrm{G}$ genotype has a protective effect against the

284 occurrence of depression in early life. As with the other SNPs included in the study, no evidence

285 was found that the $U N G$ SNP could affect the severity of the symptoms and the treatment 286 outcome (Fig. 2C,F,I).

287

Our findings are especially interesting in the light of our earlier papers reporting impairment of DNA damage repair and those by other teams suggesting disturbances of uracil metabolism in the course of depression. As mentioned in the Introduction, folate and cobalamin deficiencies may play a role in the etiology of the disease (Papakostas et al., 2005; Reynolds, 2002; Beydoun et al., 2010; Kim et al., 2008; Young, 2007; Araújo et al., 2015). In the brain, both of these vitamins play a crucial role as cofactors in the synthesis of neurotransmitters, hormones, myelin and membrane phospholipids, as well as in epigenetic regulation (Hughes et al., 2013; Reynolds, 2006). Interestingly, they are also important for the biosynthesis of nuclear acids, particularly the formation of dTMP from dUMP. Thus, a deficiency of the vitamins causes a shifting of the balance between these two nucleoside monophosphates towards dUMP resulting in the incorporation of uracil into DNA (Reynolds, 2014). This, together with the impairment of DNA damage repair discovered by our team, that can be, at least partly, attributed to the presence of specific SNP variants, may lead to the introduction of AP sites or DNA strand breaks and apoptosis of neurons, especially in the hippocampus (Young et al. 2007; Czarny et al., 2017a). In addition, folate deficiencies are also known to affect mtDNA, causing inter alia an increased number of deletions and thus the induction of oxidative stress (Chou and Huang, 2009; Chou et al., 2007; Kronenberg et al., 2011). This suggests that the impairment of uracil metabolism may contribute to the dysfunction of mitochondria and the increased level of oxidative stress observed in depression (Araújo et al., 2015). Our results indicating that the UNG variant is associated with the decreased level of uracil in blood DNA, and a lower risk of disease development, further support this hypothesis. On the other hand, the results suggest that the studied SNPs did not influence neither the effectiveness of antidepressant therapy nor the severity of depression before and after treatment. In contrast, it was proven that folate deficiency may be associated with a bad response to therapy (Papakostas et al., 2005; Reynolds, 2002). Thus, we speculate that the impairment of uracil removal from DNA may be an adjunctive factor 
312 to the shortage of folate, which speeds up the development of depression, but affects neither the

313 severity nor the treatment of the disease. However, those assumptions must be taken with

314 caution, since the level of uracil or folate was not measured.

315 The study does have some limitations. While the sample size is relatively small, similar

316 sample sizes have been used in recently published studies concerning polymorphic variability

317 (Joung et al., 2017; Peitl et al., 2017). Moreover, due to ethnic homogeneity of the studied

318 population, results obtained by our team cannot be extrapolated to the world population.

319 Furthermore, as no expression analysis was performed of the studied genes on the mRNA or on

320 the protein level, it is not certain that the presence of the studied SNPs causes changes in the

321 expression of those genes in patients with depression.

322

323 Conclusion

324 The functional polymorphism located in $U N G$ modulated the occurrence and the onset

325 of depression, and the SMUG1 SNP affected the time of the first episode. Our results,

326 particularly the evidence of the protective effect of the $U N G$ SNP variant in patients with the

327 early-onset depression and the fact that this variant is associated with a low level of uracil,

328 suggest that disturbances of uracil removal from DNA may be an additional factor, apart from

329 folate shortage, to hasten the development of the disease. This study further supports the

330 hypothesis that DNA damage and the impairment of DNA repair are important for the

331 pathophysiology of depression. Further research, including the analysis of levels of uracil

332 incorporation into DNA of depressed patients, is needed to elucidate the potential casual-effect

333 mechanisms. 
336

337

338

339

340

341

342

343

344

345

346

347

348

349

350

351

352

353

354

355

356

357

358

359

360

361

362

363

364

365

366

367

368

\section{Reference}

Akiskal, H.S., Lewis, L.J., 2005. The depressive spectrum: re-conceptualizing the relationship between dysthymic, sub-threshold and major depressions. In: Licinio, J., Wong, M.-L. (Eds.), Biology of Depression: From Novel Insights to Therapeutic Strategies. Wiley-VCH Verlag GmbH \& Co., Weinheim GmbH \& Co., Weinheim, pp. 47-70.

Alcocer-Gómez, E., de Miguel, M., Casas-Barquero, N., Núñez-Vasco, J., Sánchez-Alcazar, J.A., Fernández-Rodríguez, A., Cordero, M.D., 2014. NLRP3 inflammasome is activated inmononuclear blood cells from patients with major depressive disorder. Brain Behav. Immun. 36, 111-117.

An, Q., Robins, P., Lindahl, T., Barnes, D.E., 2005. C --> T mutagenesis and gamma-radiation sensitivity due to deficiency in the Smug1 and Ung DNA glycosylases. EMBO J. 24, 2205-2513.

Anderson, G., Maes, M., 2014. Oxidative/nitrosative stress and immuno-inflammatorypathways in depression: treatment implications. Curr. Pharm. Des. 20, 3812-3847.

Andersen, S., Ericsson, M., Dai, H.Y., Peña-Diaz, J., Slupphaug, G., Nilsen, H., Aarset, H., Krokan, H.E., 2005a. Monoclonal B-cell hyperplasia and leukocyte imbalance precede development of B-cell malignancies in uracil-DNA glycosylase deficient mice. DNA Repair (Amst). 4, 1432-1441.

Andersen, S., Heine, T., Sneve, R., König, I., Krokan, H.E., Epe, B., Nilsen, H., $2005 b$. Incorporation of dUMP into DNA is a major source of spontaneous DNA damage, while excision of uracil is not required for cytotoxicity of fluoropyrimidines in mouse embryonic fibroblasts. Carcinogenesis. 26, 547-555.

Araújo, J.R., Martel, F., Borges, N., Araújo, J.M., Keating, E., 2015. Folates and aging: Role in mild cognitive impairment, dementia and depression. Ageing Res. Rev. 22, 9-19.

Beydoun, M.A., Shroff, M.R., Beydoun, H.A., Zonderman, A.B., 2010. Serum folate, vitamin B12 , and homocysteine and their association with depressive symptoms among U.S. adults.

Psychosom. Med. 72, 862-873.

Black, C.N., Bot, M., Scheffer, P.G., Cuijpers, P., Penninx, B.W., 2015. Is depression associatedwith increased oxidative stress? A systematic review and metaanalysis.Psychoneuroendocrinology. 51, 164-175.

Bonyadi, M., Mehdizadeh, F., Jabbarpoor Bonyadi, M.H., Soheilian, M., Javadzadeh, A., Yaseri, M., 2017. Association of the DNA repair SMUG1 rs3087404 polymorphism and its interaction with high sensitivity C-reactive protein for age-related macular degeneration in Iranian patients. Ophthalmic Genet. 38, 422-427. 
369 Boorstein, R.J., Cummings, A. Jr., Marenstein, D.R., Chan, M.K., Ma, Y., Neubert, T.A., Brown, 370 S.M., Teebor, G.W., 2001. Definitive identification of mammalian 5-hydroxymethyluracil DNA

371 N-glycosylase activity as SMUG1. J. Biol. Chem. 276, 41991-41997.

372 Brown, G.W., Harris, T.O., Hepworth, C., 1994. Life events and endogenous depression.

373 Apuzzle reexamined. Arch. Gen. Psychiatry. 51, 525-534.

374 Chang, J.P., Lin, C.C., Hwu, H.G., Su, K.P., 2014. View on DSM from Taiwan: transition from 375 IV to 5. Acta Psychiatr. Scand. 129, 235.

376 Chanson, A., Parnell, L.D., Ciappio, E.D., Liu, Z., Crott, J.W., Tucker, K.L., Mason, J.B., 2009.

377 Polymorphisms in uracil-processing genes, but not one-carbon nutrients, are associated with

378 altered DNA uracil concentrations in an urban Puerto Rican population. Am. J. Clin. Nutr. 89, $379 \quad 1927-1936$.

380 Chou, Y.F., Huang, R.F., 2009. Mitochondrial DNA deletions of blood lymphocytes as genetic 381 markers of low folate-related mitochondrial genotoxicity in peripheral tissues. Eur. J. Nutr. 48, $382429-436$.

383 Chou, Y.F., Yu, C.C., Huang, R.F., 2007. Changes in mitochondrial DNA deletion, content, and 384 biogenesis in folate-deficient tissues of young rats depend on mitochondrial folate and oxidative 385 DNA injuries. J. Nutr. 137, 2036-2042.

386 Czarny, P., Kwiatkowski, D., Kacperska, D., Kawczyńska, D., Talarowska, M., Orzechowska, 387 A., Bielecka-Kowalska, A., Szemraj, J., Gałecki, P., Śliwiński, T., 2015a. Elevated level of DNA 388 damage and impaired repair of oxidative DNA damage in patients with recurrent depressive 389 disorder. Med. Sci. Monit. 21, 412-418.

390 Czarny, P., Kwiatkowski, D., Galecki, P., Talarowska, M., Orzechowska, A., Bobinska, 391 K.,Bielecka-Kowalska, A., Szemraj, J., Maes, M., Su, K.P., Sliwinski, T., 2015b. Association 392 between single nucleotide polymorphisms of MUTYH, hOGG1 and NEIL1 genes, and 393 depression. J. Affect. Disord. 184, 90-96.

394 Czarny, P., Kwiatkowski, D., Toma, M., Kubiak, J., Sliwinska, A., Talarowska, M., Szemraj, J., 395 Maes, M., Galecki, P., Sliwinski, T., 2017a. Impact of Single Nucleotide Polymorphisms of Base 396 Excision Repair Genes on DNA Damage and Efficiency of DNA Repair in Recurrent Depression 397 Disorder. Mol. Neurobiol. 54, 4150-4159.

398 Czarny, P., Wigner, P., Galecki, P., Sliwinski, T., 2017b. The interplay betweeninflammation, 399 oxidative stress, DNA damage, DNA repair and mitochondrialdysfunction in depression. Prog 400 Neuropsychopharmacol. Biol. Psychiatry. 80(Pt C), 309-321.

401 Demyttenaere, K., De Fruyt, J., 2003. Getting what you ask for: on the selectivity of depression 402 rating scales. Psychothery. Psychosom. 72, 61-70. 
403 Dianov, G.L., Timchenko, T.V., Sinitsina, O.I., Kuzminov, A.V., Medvedev, O.A., Salganik, 404 R.I., 1991. Repair of uracil residues closely spaced on the opposite strands of plasmid DNA 405 results in double-strand break and deletion formation. Mol. Gen. Genet. 225, 448-452.

406 Endres, M., Biniszkiewicz, D., Sobol, R.W., Harms, C., Ahmadi, M., Lipski, A., Katchanov, J., 407 Mergenthaler, P., Dirnagl, U., Wilson, S.H., Meisel, A., Jaenisch, R., 2004. Increased 408 postischemic brain injury in mice deficient in uracil-DNA glycosylase. J. Clin. Invest. 113, 409 1711-1721.

410 Forlenza, M.J., Miller, G.E., 2006. Increased serum levels of 8-hydroxy-2'-deoxyguanosine in 411 clinical depression. Psychosom. Med. 68, 1-7.

412 Frederico, L.A., Kunkel, T.A., Shaw, B.R., 1990. A sensitive genetic assay for the detection of 413 cytosine deamination: determination of rate constants and the activation energy. Biochemistry. $41429,2532-2537$.

415 Gardner, A., Boles, R.G., 2011. Beyond the serotonin hypothesis: mitochondria,inflammation 416 and neurodegeneration in major depression and affective spectrumdisorders. Prog.

417 Neuropsychopharmacol. Biol. Psychiatry. 35, 730-743.

418 Greden, J.F., 2001. The burden of disease for treatment-resistant depression. J. Clin. Psychiatry. 41962 Suppl 16, 26-31.

420 Gruenberg, A.M., Goldstein, R.D., Pincus, H.A., 2005. Classification of depression: research and 421 diagnostic criteria: DSM-IV and ICD-10. In: Licinio, J., Wong, M.-L. (Eds.), Biology of 422 Depression: From Novel Insights to therapeutic Strategies. Wiley, Weinheim, pp. 1-12.

423 Hamilton, M., 1960. A rating scale for depression. J. Neurol. Neurosurg. Psychiatry. 23, 56-62.

424 Haug, T., Skorpen, F., Aas, P.A., Malm, V., Skjelbred, C., Krokan, H.E., 1998. Regulation of 425 expression of nuclear and mitochondrial forms of human uracil-DNA glycosylase. Nucleic Acids 426 Res. 26, 1449-1457.

427 Imai, K., Slupphaug, G., Lee, W.I., Revy, P., Nonoyama, S., Catalan, N., Yel, L., Forveille, M., 428 Kavli, B., Krokan, H.E., Ochs, H.D., Fischer, A., Durandy, A., 2003. Human uracil-DNA 429 glycosylase deficiency associated with profoundly impaired immunoglobulin class-switch 430 recombination. Nat. Immunol. 4, 1023-1028.

431 Irie, M., Asami, S., Ikeda, M., Kasai, H., 2003. Depressive state relates to femaleoxidative DNA 432 damage via neutrophil activation. Biochem. Biophys. Res. Commun. 311, 1014-1018.

433 Irie, M., Asami, S., Nagata, S., Ikeda, M., Miyata, M., Kasai, H., 2001. Psychosocial factors asa 434 potential trigger of oxidative DNA damage in human leukocytes. Jpn. J. Cancer. Res. 92, 367435376. 
436 Iwata, M., Ota, K.T., Duman, R.S., 2013. The inflammasome: pathways linking

437 psychologicalstress, depression, and systemic illnesses. Brain Behav. Immun. 31, 105-114.

438 Jobert, L., Skjeldam, H.K., Dalhus, B., Galashevskaya, A., Vågbø, C.B., Bjørås, M., Nilsen, H., 439 2013. The human base excision repair enzyme SMUG1 directly interacts with DKC1 and 440 contributes to RNA quality control. Mol. Cell. 49, 339-345.

441 Jung, W.Y., Kim, S.G., Kim, J.H., Lee, J.S., 2017. Calcium/calmodulin-dependent protein kinase 442 IV gene polymorphisms in Korean alcohol-dependent patients. Prog. Neuropsychopharmacol. 443 Biol. Psychiatry. 79(Pt B), 386-391.

444 Lindqvist, D., Dhabhar, F.S., James, S.J., Hough, C.M., Jain, F.A., Bersani, F.S., Reus, 445 V.I., Verhoeven, J.E., Epel, E.S., Mahan, L., Rosser, R., Wolkowitz, O.M., Mellon, S.H., 2017. 446 Oxidativestress, inflammation and treatment response in major depression.

447 Psychoneuroendocrinology. 76, 197-205.

448 Lu, D.Y., Leung, Y.M., Su, K.P., 2013. Interferon- $\alpha$ induces nitric oxide synthase expression and 449 haem oxygenase-1 down-regulation in microglia: implications of cellular mechanism of IFN- $\alpha-$ induced depression. Int. J. Neuropsychopharmacol. 16, 433-444.

Kavli, B., Sundheim, O., Akbari, M., Otterlei, M., Nilsen, H., Skorpen, F., Aas, P.A., Hagen, L., Krokan, H.E., Slupphaug, G., 2002. hUNG2 is the major repair enzyme for removal of uracil from U:A matches, U:G mismatches, and U in single-stranded DNA, with hSMUG1 as a broad specificity backup. J. Biol. Chem. 277, 39926-39936.

Kessler, R.C., 2004. Epidemiology of women and depression. J. Affect. Disord. 74, 5-13.

456

457

458

459

460

461

462

463 464

465

466

467

468

469

Kim, J.M., Stewart, R., Kim, S.W., Yang, S.J., Shin, I.S., Yoon, J.S., 2008. Predictive value of folate, vitamin B12 and homocysteine levels in late-life depression. Br. J. Psychiatry. 192, 268274.

Kronenberg, G., Gertz, K., Overall, R.W., Harms, C., Klein, J., Page, M.M., Stuart, J.A., Endres, M., 2011. Folate deficiency increases mtDNA and D-1 mtDNA deletion in aged brain of mice lacking uracil-DNA glycosylase. Exp. Neurol. 228, 253-258.

Kupper, N., Gidron, Y., Winter, J., Denollet, J., 2009. Association between type D personality, depression, and oxidative stress in patients with chronic heart failure. Psychosom. Med. 71, 973780 .

Lindahl, T., 1993. Instability and decay of the primary structure of DNA. Nature. 362, 709-715.

Masaoka, A., Matsubara, M., Hasegawa, R., Tanaka, T., Kurisu, S., Terato, H., Ohyama, Y., Karino, N., Matsuda, A., Ide, H., 2003. Mammalian 5-formyluracil-DNA glycosylase. 2. Role of SMUG1 uracil-DNA glycosylase in repair of 5-formyluracil and other oxidized and deaminated base lesions. Biochemistry. 42, 5003-5012. 
470 Murray, C.J., Lopez, A.D., 1997. Alternative projections of mortality and disability bycause 471 1990-2020: Global Burden of Disease Study. Lancet. 349, 1498-1504.

472 Maes, M., Mihaylova, I., Kubera, M., Uytterhoeven, M., Vrydags, N., Bosmans, E., 2009.

473 Increased 8-hydroxy-deoxyguanosine, a marker of oxidative damage to DNA, in

474 majordepression and myalgic encephalomyelitis / chronic fatigue syndrome. Neuro. Endocrinol.

475 Lett. 30, 715-722.

476 Nadeau, J.H., 2002. Single nucleotide polymorphisms: tackling complexity. Nature. 420, 517-

477518.

478 Nilsen, H., Otterlei, M., Haug, T., Solum, K., Nagelhus, T.A., Skorpen, F., Krokan, H.E., 1997.

479 Nuclear and mitochondrial uracil-DNA glycosylases are generated by alternative splicing and

480 transcription from different positions in the UNG gene. Nucleic Acids Res. 25, 750-755.

481 Nilsen, H., Stamp, G., Andersen, S., Hrivnak, G., Krokan, H.E., Lindahl, T., Barnes, D.E., 2003.

482 Gene-targeted mice lacking the Ung uracil-DNA glycosylase develop B-cell lymphomas.

483 Oncogene. 22, 5381-5386.

484 Papakostas, G.I., Petersen, T., Lebowitz, B.D., Mischoulon, D., Ryan, J.L., Nierenberg, A.A., 485 Bottiglieri, T., Alpert, J.E., Rosenbaum, J.F., Fava, M., 2005. The relationship between serum 486 folate, vitamin B12, and homocysteine levels in major depressive disorder and the timing of 487 improvement with fluoxetine. Int. J. Neuropsychopharmacol. 8, 523-528.

488 Parker, G., 2000. Classifying depression: should paradigms lost be regained? Am. J. Psychiatry. $489157,1195-1203$.

490 Pasco, J.A., Nicholson, G.C., Williams, L.J., Jacka, F.N., Henry, M.J., Kotowicz, M.A., 491 Schneider, H.G., Leonard, B.E., Berk, M., 2010. Association of high-sensitivity C492 reactiveprotein with de novo major depression. Br. J. Psychiatry. 197, 372-377.

493 Patten, S., 1997. Performance of the Composite International Diagnostic Interview Short Form 494 for major depression in community and clinical samples. Chron. Dis. Can. 3, 18-24.

495 Peitl, V., Štefanović, M., Karlović, D., 2017. Depressive symptoms in schizophrenia and 496 dopamine and serotonin gene polymorphisms. Prog. Neuropsychopharmacol. Biol. Psychiatry. $497 \quad 77,209-215$.

498 Pettersen, H.S., Sundheim, O., Gilljam, K.M., Slupphaug, G., Krokan, H.E., Kavli, B., 2007. 499 Uracil-DNA glycosylases SMUG1 and UNG2 coordinate the initial steps of base excision repair 500 by distinct mechanisms. Nucleic Acids Res. 35, 3879-3892.

501 Reynolds, E.H., 2002. Folic acid, ageing, depression, and dementia. BMJ. 324, 1512-1515. 
502 Rodrigues, R., Petersen, R.B., Perry, G., 2014. Parallels between major depressive disorder and 503 Alzheimer's disease: role of oxidative stress and genetic vulnerability. Cell. Mol. Neurobiol. 34, $504925-949$.

505 Sousa, M.M., Krokan, H.E., Slupphaug, G., 2007. DNA-uracil and human pathology. Mol. 506 Aspects Med. 28, 276-306.

507 Starkstein, S.E., Jorge, R., Mizrahi, R., Robinson, R.G., 2005. The construct of minor andmajor 508 depression in Alzheimer's disease. Am. J. Psychiatry. 162, 2086-2093.

509 Synowiec, E., Wysokinski, D., Zaras, M., Kolodziejska, U., Stoczynska-Fidelus, E., Janik, K., 510 Szaflik, J., Blasiak, J., Szaflik, J.P., 2014. Association between polymorphism of the DNA repair 511 SMUG1 and UNG genes and age-related macular degeneration. Retina. 34, 38-47.

512 Verri, A., Mazzarello, P., Biamonti, G., Spadari, S., Focher, F., 1990. The specific binding of 513 nuclear protein(s) to the cAMP responsive element (CRE) sequence (TGACGTCA) is reduced 514 by the misincorporation of $U$ and increased by the deamination of C. Nucleic Acids Res. 18, $515 \quad 5775-5780$.

516 Visnes, T., Doseth, B., Pettersen, H.S., Hagen, L., Sousa, M.M., Akbari, M., Otterlei, M., Kavli, 517 B., Slupphaug, G., Krokan, H.E., 2009. Uracil in DNA and its processing by different DNA 518 glycosylases. Philos Trans R Soc. Lond. B. Biol. Sci. 364, 563-568.

519 Wei, Y.C., Zhou, F.L., He, D.L., Bai, J.R., Ding, H., Wang, X.Y., Nan, K.J., 2009. Oxidative 520 stress in depressive patients with gastric adenocarcinoma. Int. J. Neuropsychopharmacol. 12, $521 \quad 1089-1096$.

522 International Statistical Classification of Diseases and Related Health Problems 10th Revision 523 (ICD-10). Geneva, World Health Organization. 2015.

524 Young, S.N., 2007. Folate and depression--a neglected problem. J. Psychiatry Neurosci. 32, 8052582. 


\section{Figure 1 (on next page)}

Impact of single-nucleotide polymorphisms localized in uracil-processing genes on age of depression onset.

Results are presented as scatter dot plots, horizontal lines represent median, and whiskers denote interquartile range. 
A DUT g.48346598G>T (rs4775748)

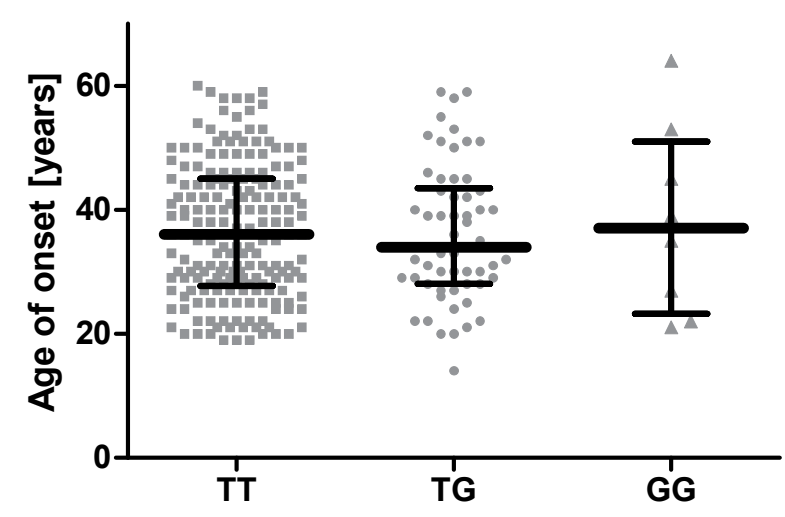

B SMUG1 c.-31A>G(rs3087404)

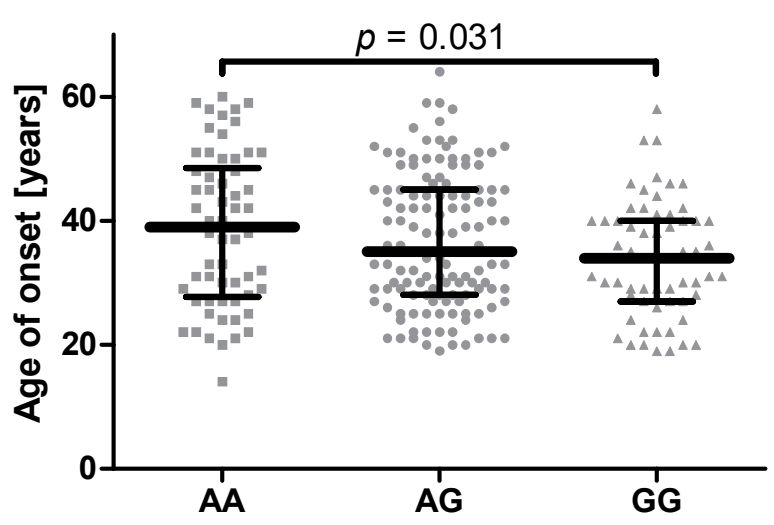

C UNG g.7245G $>$ C (rs34259)

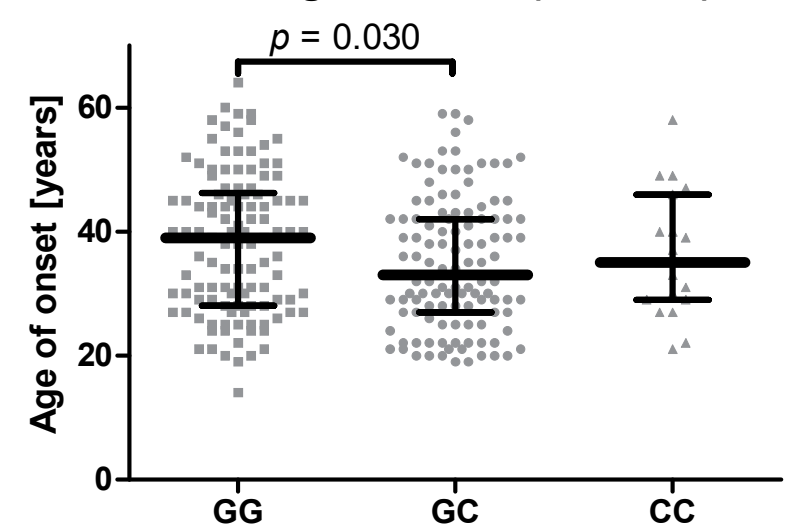




\section{Figure 2 (on next page)}

Impact of single-nucleotide polymorphisms localized in uracil-processing genes on severity of the episode before and after therapy, and on treatment effectiveness.

(A-C) Severity of current episode according to 21-item Hamilton Depression Rating Scale (HAM-D). (D-F) Severity after treatment according to HAM-D. (G-I) Treatment effectiveness expressed as percentage of HAM-D decline after treatment. Results are present as scatter dot plots, horizontal lines represent median, and whiskers denote interquartile range. In all cases $p>0.05$. 
A DUT g.48346598G >T (rs4775748)

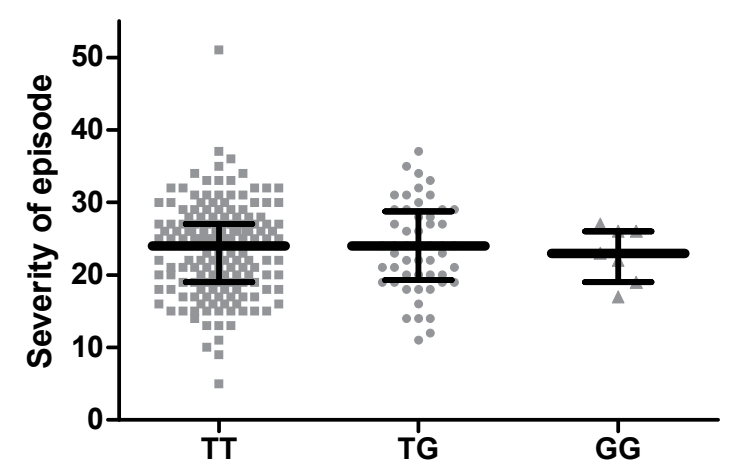

D DUT g.48346598G $>$ T (rs4775748)

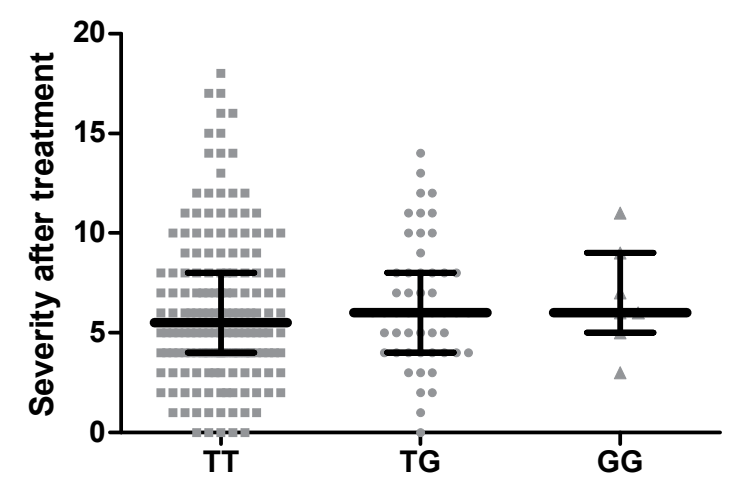

G DUT g.48346598G>T (rs4775748)

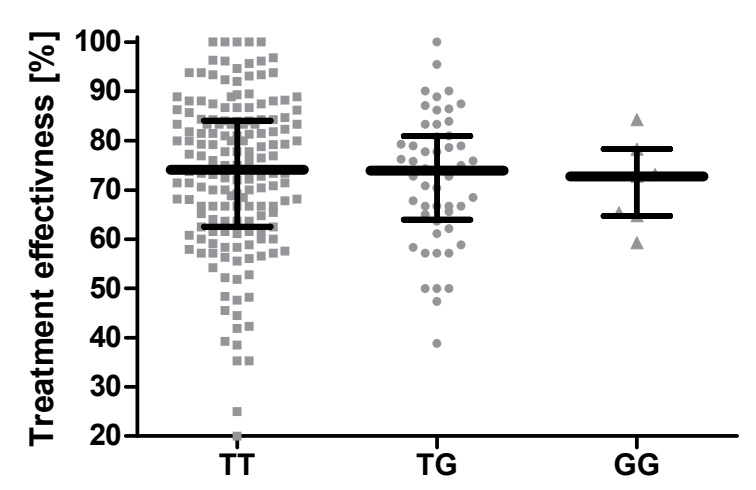

B

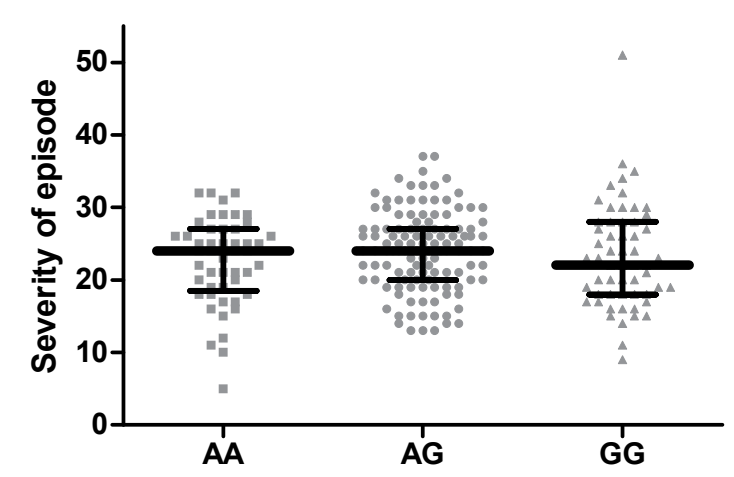

E

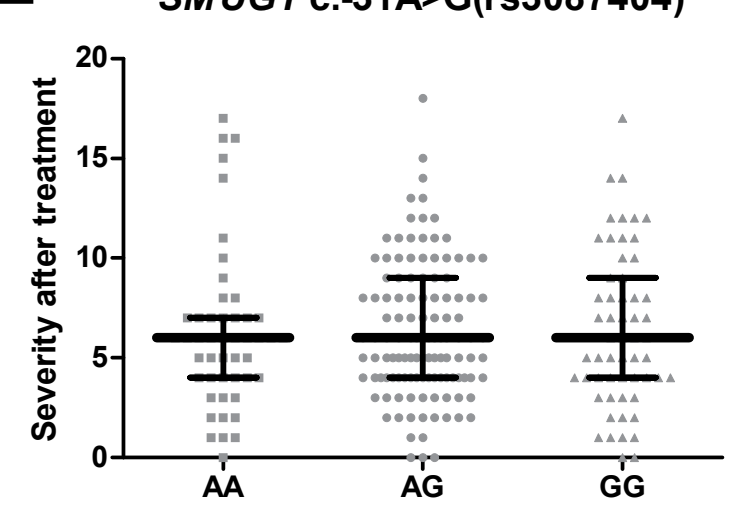

H

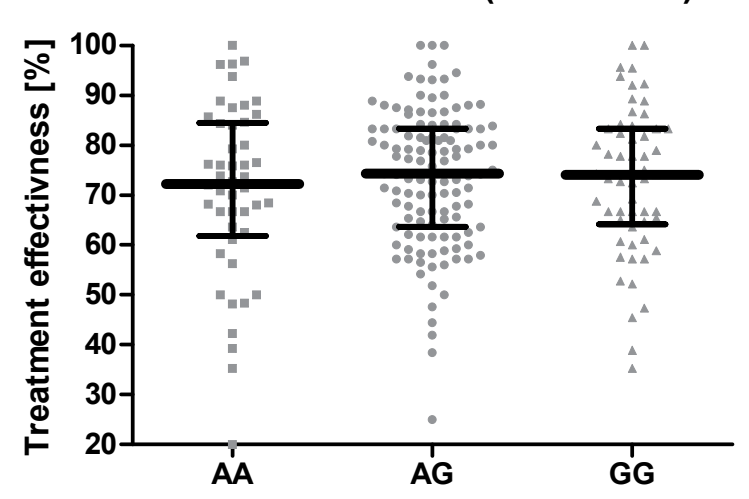

C UNG g.7245G $>C(\mathrm{rs} 34259)$

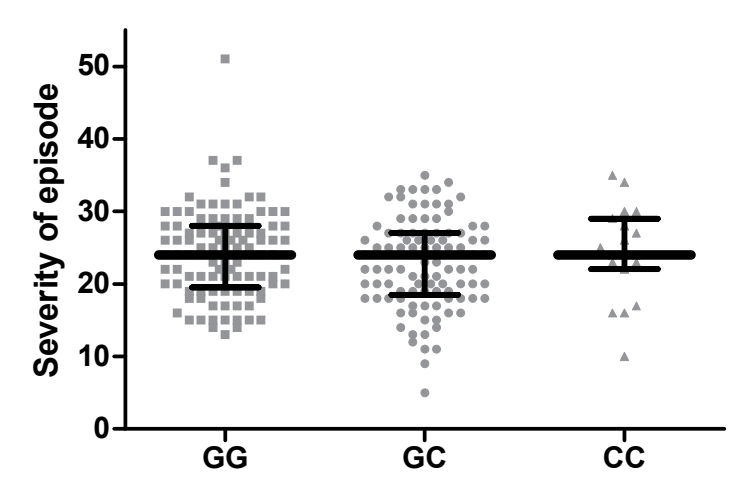

$\mathbf{F}$

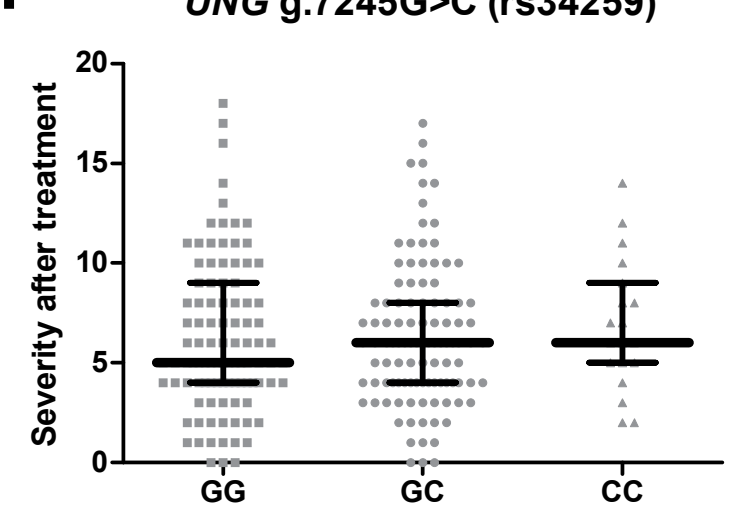

I UNG g.7245G>C (rs34259)

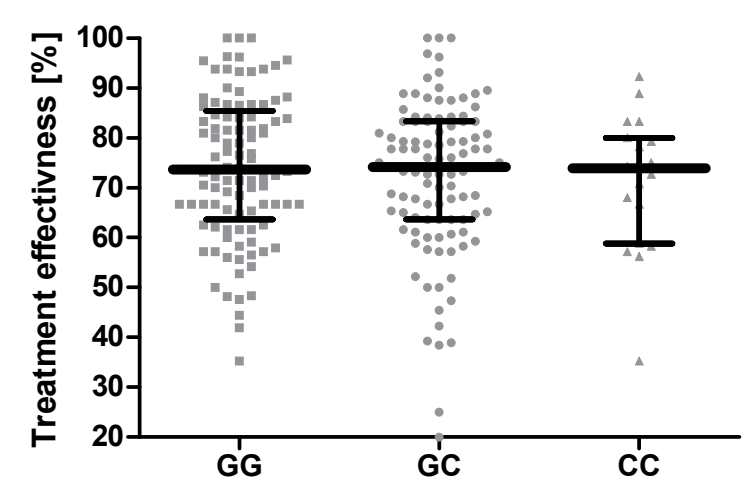




\section{Table 1 (on next page)}

The detailed characteristic of patients which were qualified the study. 


\begin{tabular}{cll}
\hline $\begin{array}{c}\text { Depression severity } \\
\text { (HAM-D range of scores) }\end{array}$ & $\begin{array}{l}\text { Percentage of patients } \\
\text { before treatment }\end{array}$ & $\begin{array}{l}\text { Percentage of patients } \\
\text { after treatment } \\
68.00 \%^{*}\end{array}$ \\
None $(0-7)$ & $0.41 \%$ & $30.67 \%^{*}$ \\
Mild $(8-16)$ & $13.11 \%$ & $1.33 \%^{*}$ \\
Moderate $(17-23)$ & $34.43 \%$ & $0 \%{ }^{*}$ \\
Severe $(\geq 24)$ & $52.05 \%$ & $49.34 \pm 10.32^{\#}$ \\
\hline Mean age of patients \pm SD & $51.39 \pm 13.37$ \\
\hline Mean age of controls \pm SD & $146 / 136$ \\
\hline Gender (male/female) of patients & $155 / 148 \%$ \\
\hline Gender (male/female) of controls & Percentage of patients \\
\hline Duration of disease from the first episode & $52.00 \%$ \\
$0-10$ years & $19.56 \%$ \\
$11-20$ years & $17.78 \%$ \\
$21-30$ years & $9.78 \%$ \\
$31-40$ years & $0.89 \%$ \\
$\geq 41$ years & Percentage of patients \\
\hline Number of episodes & $13.78 \%$ \\
1 & $31.11 \%$ \\
3 & $32.00 \%$ \\
4 & $18.22 \%$ \\
5 & $4.44 \%$ \\
6 & $0.44 \%$ \\
\hline
\end{tabular}

1 Significance of comparisons estimated with the Yates-corrected chi ${ }^{2}$ test or the Fisher exact test $2 \& P=0.881$ vs. patients; ${ }^{*} P<0.0001 ;{ }^{*} P=0.225$ vs. controls 


\section{Table 2 (on next page)}

Association between the studied single-nucleotide polymorphism and depression.

Table presents a distribution of genotypes and alleles of DUT g.48346598G > T (rs4775748),

SMUG1 c.-31A >G(rs3087404) and UNG g.7245G>C (rs34259) single-nucleotide polymorphisms, and OR with $95 \% \mathrm{Cl}$ in groups of patients with rDD and controls without mental disorders. 


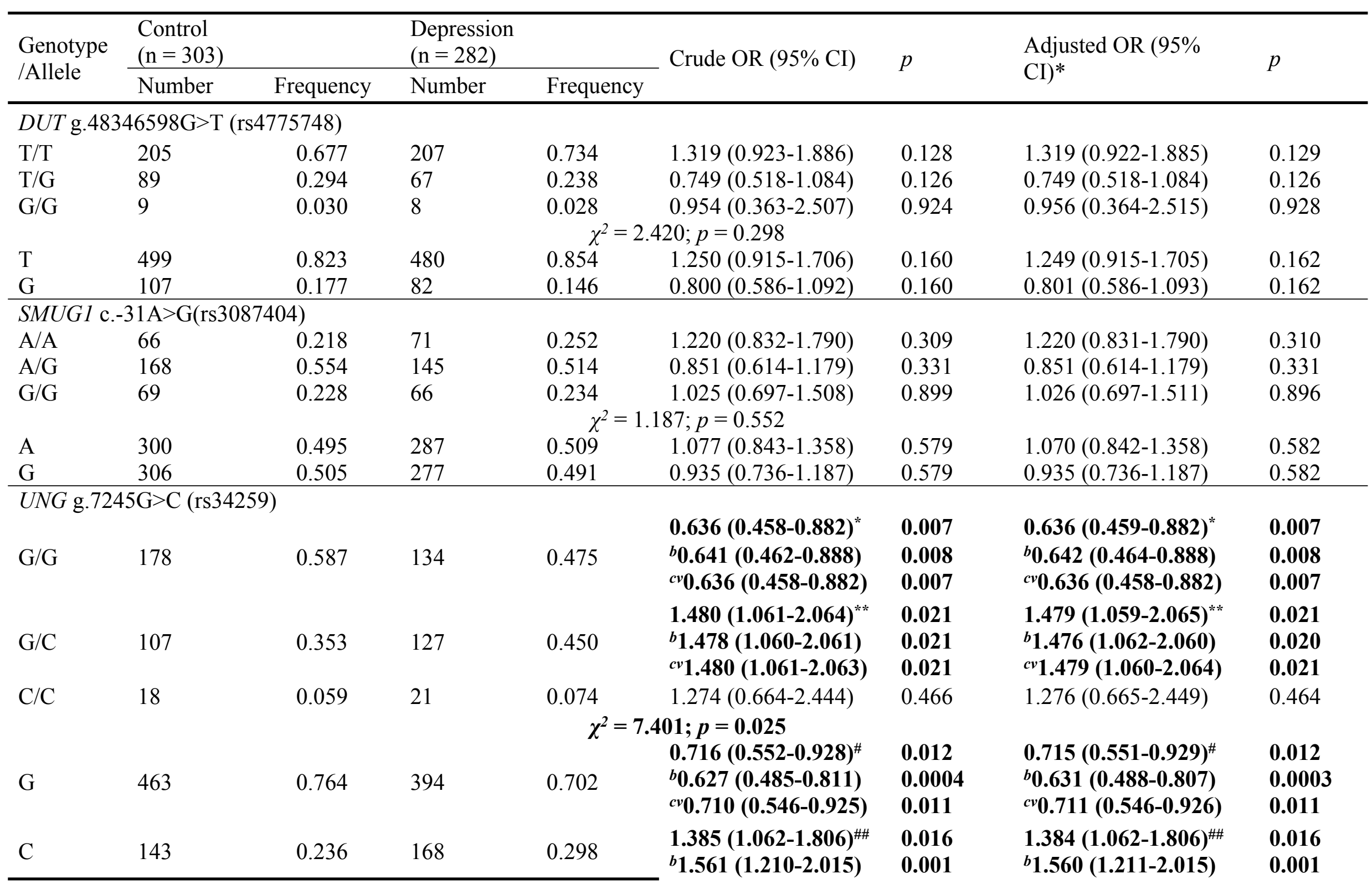


${ }^{c v} 1.385(1.063-1.805) \quad 0.016 \quad c v 1.385(1.062-1.805)$

1 * OR adjusted for sex; the superscript ${ }^{b}$ means the bootstrap-boosted OR (resampling with replacement, 10000 iterations); ${ }^{c v}$ means the crossvalidated OR. Statistical power (1- $\beta$ ) for significant comparisons given for the ranges: ${ }^{*} 0.782-0.791,{ }^{* *} 0.647-0.654,{ }^{\#} 0.353-0.361$ and ${ }^{\# \#} 0.426-$ 0.435. $P_{\text {Hosmer-Lemeshow }}=0.296-0.969$ for all significant comparisons.

$4 \quad p<0.05$ along with corresponding ORs are in bold 


\section{Table 3(on next page)}

Association between the combined genotypes of the studied single-nucleotide polymorphism and depression.

Table presents a distribution of combined genotypes of DUT rs4775748, SMUG rs3087404 and UNG rs34259 single-nucleotide polymorphisms, and OR with $95 \% \mathrm{Cl}$ in groups of patients with rDD and controls without mental disorders. 


\begin{tabular}{|c|c|c|c|c|c|c|c|c|}
\hline \multirow{2}{*}{$\begin{array}{l}\text { Combined } \\
\text { genotype }\end{array}$} & \multicolumn{2}{|c|}{ Control $(n=303)$} & \multicolumn{2}{|c|}{ Depression $(\mathrm{n}=282)$} & \multirow{2}{*}{ Crude OR $(95 \%$ CI $)$} & \multirow{2}{*}{$p$} & \multirow{2}{*}{ Adjusted OR (95\% CI) } & \multirow{2}{*}{$p$} \\
\hline & Number & Frequency & Number & Frequency & & & & \\
\hline \multicolumn{9}{|c|}{$D U T(\mathrm{rs} 4775748), S M U G 1$ c.-31A $>\mathrm{G}(\mathrm{rs} 3087404)$ and $U N G(\mathrm{rs} 34259)$} \\
\hline $\mathrm{T} / \mathrm{T}-\mathrm{A} / \mathrm{A}-\mathrm{G} / \mathrm{G}$ & 37 & 0.122 & 27 & 0.096 & $\begin{array}{l}0.761(0.450-1.287) \\
3.402(1.423-8.133)^{0.892}\end{array}$ & 0.308 & $0.758(0.448-1.283)$ & 0.303 \\
\hline $\mathrm{T} / \mathrm{T}-\mathrm{A} / \mathrm{A}-\mathrm{G} / \mathrm{C}$ & 7 & 0.023 & 21 & 0.074 & $\begin{array}{l}3.402(1.423-8.133)^{0.892} \\
{ }^{b} 3.411(1.425-8.161) \\
{ }^{c} 3.402(1.423-8.133)\end{array}$ & $\begin{array}{l}0.006 \\
0.006 \\
0.006\end{array}$ & $\begin{array}{l}3.401(1.422-8.134)^{0.875} \\
{ }^{b} 3.410(1.424-8.163) \\
{ }^{c} 3.401(1.422-8.134)\end{array}$ & $\begin{array}{l}0.006 \\
0.006 \\
0.006\end{array}$ \\
\hline $\mathrm{T} / \mathrm{T}-\mathrm{A} / \mathrm{A}-\mathrm{C} / \mathrm{C}$ & 2 & 0.007 & 4 & 0.014 & $2.165(0.394-11.915)$ & 0.374 & $2.166(0.394-11.921)$ & 0.374 \\
\hline $\mathrm{T} / \mathrm{T}-\mathrm{A} / \mathrm{G}-\mathrm{G} / \mathrm{G}$ & 58 & 0.191 & 52 & 0.184 & $0.955(0.630-1.447)$ & 0.828 & $0.956(0.631-1.449)$ & 0.833 \\
\hline $\mathrm{T} / \mathrm{T}-\mathrm{A} / \mathrm{G}-\mathrm{G} / \mathrm{C}$ & 46 & 0.152 & 49 & 0.174 & $1.175(0.757-1.824)$ & 0.472 & $1.174(0.756-1.822)$ & 0.476 \\
\hline $\mathrm{T} / \mathrm{T}-\mathrm{A} / \mathrm{G}-\mathrm{C} / \mathrm{C}$ & 3 & 0.010 & 5 & 0.018 & $1.805(0.427-7.623)$ & 0.422 & $1.806(0.428-7.627)$ & 0.421 \\
\hline $\mathrm{T} / \mathrm{T}-\mathrm{G} / \mathrm{G}-\mathrm{G} / \mathrm{G}$ & 29 & 0.096 & 24 & 0.085 & $0.879(0.499-1.549)$ & 0.655 & $0.880(0.499-1.552)$ & 0.659 \\
\hline T/T-G/G-G/C & 20 & 0.066 & 19 & 0.067 & $1.022(0.534-1.958)$ & 0.947 & $1.024(0.534-1.961)$ & 0.944 \\
\hline T/T-G/G-C/C & 3 & 0.010 & 6 & 0.021 & $2.174(0.538-8.776)$ & 0.275 & $2.172(0.538-8.769)$ & 0.276 \\
\hline T/G-A/A-G/G & 7 & 0.023 & 7 & 0.025 & $1.076(0.373-3.108)$ & 0.892 & $1.083(0.374-3.136)$ & 0.883 \\
\hline T/G-A/A-G/C & 8 & 0.026 & 10 & 0.035 & $1.356(0.527-3.485)$ & 0.528 & $1.352(0.525-3.479)$ & 0.532 \\
\hline \multirow[t]{2}{*}{$\mathrm{T} / \mathrm{G}-\mathrm{A} / \mathrm{A}-\mathrm{C} / \mathrm{C}$} & 3 & 0.010 & 1 & 0.004 & $0.356(0.037-3.441)$ & 0.372 & $0.358(0.037-3.463)$ & 0.375 \\
\hline & & & & & $0.492(0.265-0.915)^{0.767}$ & 0.025 & $0.491(0.264-0.914)^{0.765}$ & 0.025 \\
\hline \multirow[t]{2}{*}{$\mathrm{T} / \mathrm{G}-\mathrm{A} / \mathrm{G}-\mathrm{G} / \mathrm{G}$} & 33 & 0.109 & 16 & 0.057 & ${ }^{b} 0.496(0.267-0.922)$ & 0.027 & ${ }^{b} 0.495(0.266-0.921)$ & 0.026 \\
\hline & & & & & ${ }^{c v} 0.492(0.265-0.915)$ & 0.025 & ${ }^{c} v 0.491(0.264-0.914)$ & 0.025 \\
\hline $\mathrm{T} / \mathrm{G}-\mathrm{A} / \mathrm{G}-\mathrm{G} / \mathrm{C}$ & 19 & 0.053 & 16 & 0.057 & $0.899(0.453-1.785)$ & 0.761 & $0.898(0.452-1.784)$ & 0.759 \\
\hline $\mathrm{T} / \mathrm{G}-\mathrm{A} / \mathrm{G}-\mathrm{C} / \mathrm{C}$ & 4 & 0.013 & 1 & 0.004 & $0.266(0.030-2.394)$ & 0.238 & $0.267(0.030-2.401)$ & 0.238 \\
\hline $\mathrm{T} / \mathrm{G}-\mathrm{G} / \mathrm{G}-\mathrm{G} / \mathrm{G}$ & 9 & 0.030 & 6 & 0.021 & $0.710(0.250-2.021)$ & 0.521 & $0.712(0.250-2.028)$ & 0.525 \\
\hline $\mathrm{T} / \mathrm{G}-\mathrm{G} / \mathrm{G}-\mathrm{G} / \mathrm{C}$ & 4 & 0.013 & 8 & 0.028 & $2.182(0.650-7.329)$ & 0.207 & $2.189(0.652-7.356)$ & 0.205 \\
\hline T/G-G/G-C/C & 2 & 0.007 & 2 & 0.007 & $1.075(0.150-7.683)$ & 0.943 & $1.069(0.149-7.651)$ & 0.947 \\
\hline $\mathrm{G} / \mathrm{G}-\mathrm{A} / \mathrm{A}-\mathrm{G} / \mathrm{G}$ & 2 & 0.007 & 0 & 0.000 & - & - & - & - \\
\hline $\mathrm{G} / \mathrm{G}-\mathrm{A} / \mathrm{A}-\mathrm{G} / \mathrm{C}$ & 0 & 0.000 & 0 & 0.000 & - & - & - & - \\
\hline $\mathrm{G} / \mathrm{G}-\mathrm{A} / \mathrm{A}-\mathrm{C} / \mathrm{C}$ & 0 & 0.000 & 1 & 0.004 & - & - & - & - \\
\hline G/G-A/G-G/G & 1 & 0.003 & 2 & 0.007 & $2.157(0.195-23.921)$ & 0.531 & $2.150(0.194-23.852)$ & 0.533 \\
\hline G/G-A/G-G/C & 3 & 0.010 & 4 & 0.014 & $1.439(0.319-6.486)$ & 0.636 & $1.437(0.319-6.478)$ & 0.637 \\
\hline G/G-A/G-C/C & 1 & 0.003 & 0 & 0.000 & - & - & - & - \\
\hline $\mathrm{G} / \mathrm{G}-\mathrm{G} / \mathrm{G}-\mathrm{G} / \mathrm{G}$ & 2 & 0.007 & 0 & 0.000 & - & - & - & - \\
\hline $\mathrm{G} / \mathrm{G}-\mathrm{G} / \mathrm{G}-\mathrm{G} / \mathrm{C}$ & 0 & 0.000 & 0 & 0.000 & - & - & - & - \\
\hline $\mathrm{G} / \mathrm{G}-\mathrm{G} / \mathrm{G}-\mathrm{C} / \mathrm{C}$ & 0 & 0.000 & 1 & 0.004 & - & - & - & - \\
\hline
\end{tabular}


1 * OR adjusted for sex; the superscript ${ }^{b}$ means the bootstrap-boosted OR (resampling with replacement, 10000 iterations); ${ }^{c v}$ means the cross-

2 validated OR. Statistical power (1- $\beta$ ) for significant comparisons given in superscripts.

$3 p<0.05$ along with corresponding ORs are in bold 


\section{Table 4(on next page)}

Association between the studied single-nucleotide polymorphism and the onset of depression.

Table presents a distribution of genotypes and alleles of DUT rs4775748, SMUG rs3087404 and UNG rs34259 single-nucleotide polymorphisms, and OR with $95 \% \mathrm{Cl}$ in group of patients with rDD that had their first episode before 35 years of age (marked as early onset depression) or after 35 years of age (marked as late onset depression), when compared to the control group without mental disorders. 


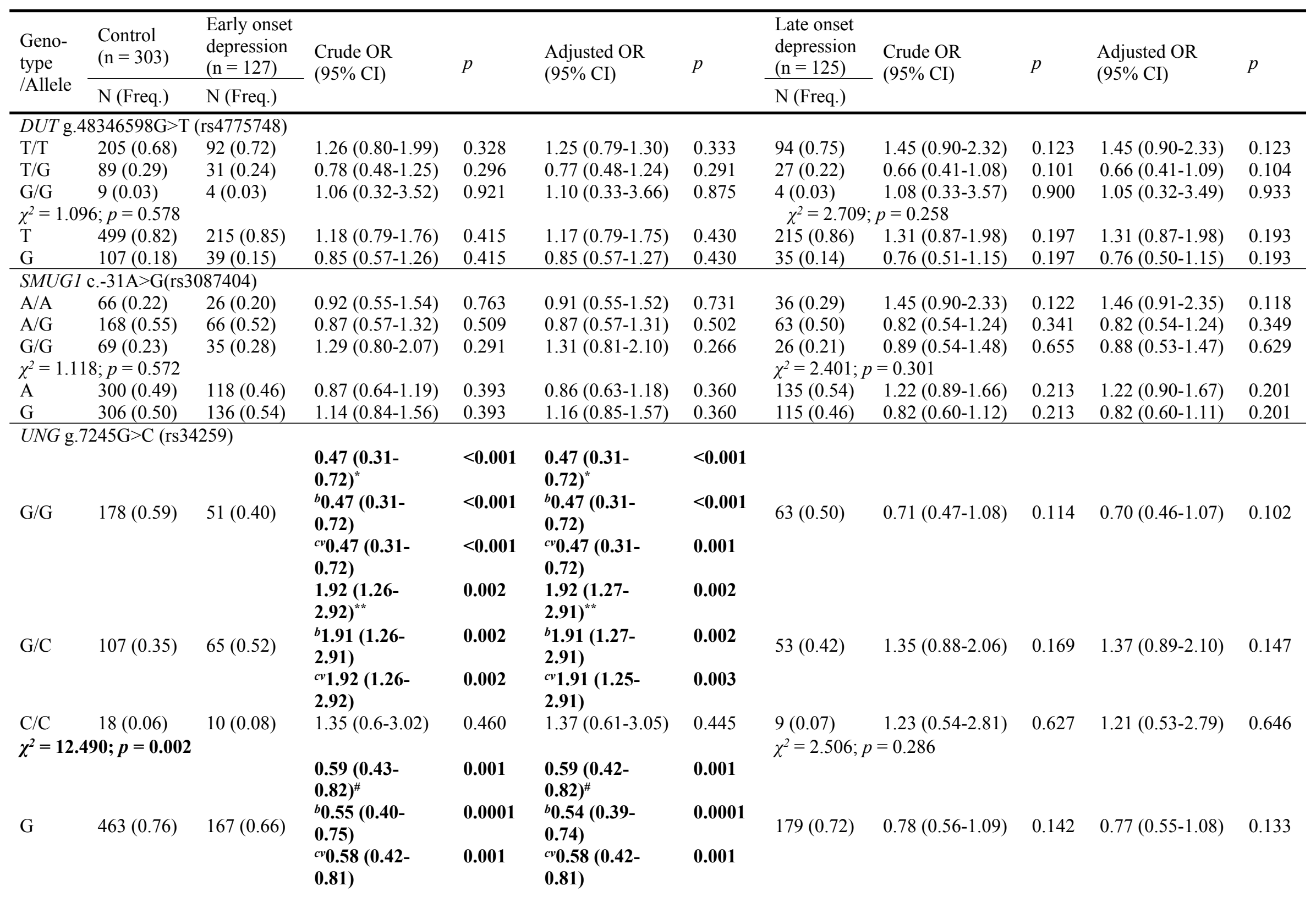




\begin{tabular}{|c|c|c|c|c|c|c|c|c|c|c|c|}
\hline \multirow{3}{*}{ C } & \multirow{3}{*}{$143(0.24)$} & \multirow{3}{*}{$85(0.34)$} & $1.63(1.18-$ & 0.003 & $1.65(1.20-$ & 0.002 & \multirow{3}{*}{$71(0.28)$} & \multirow{3}{*}{$1.28(0.92-1.79)$} & \multirow{3}{*}{0.142} & \multirow{3}{*}{$1.29(0.92-1.80)$} & \multirow{3}{*}{0.133} \\
\hline & & & $\begin{array}{l}2.24)^{\# \#} \\
{ }^{\# 1.46}(1.06- \\
2.01)\end{array}$ & 0.02 & $\begin{array}{l}2.24)^{\# \#} \\
{ }^{\prime} 1.51(1.09- \\
2.08)\end{array}$ & 0.01 & & & & & \\
\hline & & & $\begin{array}{l}{ }^{c} 1.66(1.19- \\
2.31)\end{array}$ & 0.003 & $\begin{array}{l}{ }^{c} 1.66(1.19- \\
2.31)\end{array}$ & 0.003 & & & & & \\
\hline
\end{tabular}

* OR adjusted for sex; the superscript ${ }^{b}$ means the bootstrap-boosted OR (resampling with replacement, 10000 iterations); ${ }^{c v}$ means the crossvalidated OR. Statistical power (1- $\beta$ ) for significant comparisons given for the ranges: ${ }^{*} 0.970-0.971,{ }^{* *} 0.916-0.921,{ }^{\#} 0.831-0.832$ and ${ }^{\# \#} 0.576-$ 0.597. $P_{\text {Hosmer-Lemeshow }}=0.152-0.999$ for all significant comparisons.

$5 \quad p<0.05$ along with corresponding ORs are in bold 